\title{
Patient load and medical staffing in adult dialysis units in the United Kingdom
}

\author{
WILLIAM K STEWART, LAURA W FLEMING
}

\begin{abstract}
A survey of medical staffing in $\mathbf{5 0}$ adult dialysis units in the United Kingdom in 1986 showed a wide range of patient to staff ratios or staffing score ratios. The total patient load (patients receiving haemodialysis in hospital and at home and those receiving continuous ambulatory peritoneal dialysis) varied from 12 to 270 per unit. Patients receiving acute haemodialysis or who had received a transplant were not included. The unit staffing score, on a weighted scale based on experience, varied from $6 \cdot 0$ to $40 \cdot 5$. Previous surveys have all been regionally or nationally based so criteria for assessing the adequacy of staffing in single units do not exist. This survey attempts to provide a guideline by describing the range of medical staffing compared with patient load in single dialysis units. No unit considered itself to be overstaffed, and several considered themselves to be greatly understaffed.

Individual dialysis units should plead their own case in the light of their own circumstances and up to date information provided in nationwide staffing surveys such as this one.
\end{abstract}

\section{Introduction}

Although many reports have highlighted th? problems of providing a dialysis service for patients with renal failure, ${ }^{1.3}$ few have concentrated on the issue of manpower versus workload. Jones et al did report on this issue on a regional basis,${ }^{4}$ but there is no up to date information on workload and manpower in single units. There are

\footnotetext{
University Department of Medicine, Ninewells Hospital and Medical School, Dundee DD1 9SY

WILLIAM K STEWART, MD, PHD, senior lecturer in medicine LAURA W FLEMING, BSC, senior scientific officer

Correspondence and requests for reprints to: Dr Stewart.
}

therefore no norms against which to decide whether a unit is understaffed. Estimates derived from the number of staff or patients/million of the population can be wrong, as this ratio varies from area to area and, indeed, from country to country. ${ }^{6}$

Assertions of understaffing based on the subjective experience of those directly concerned usually go unheeded. Objective standards are difficult to find or virtually non-existent even for the most obvious of hospital functions-for example, nursing in a general medical or surgical ward. ${ }^{7}$ The effect on nursing or medical staff in specialised work such as intensive care or dialysis is worse. ${ }^{8}$ Staff may feel themselves to be overworked, but the employer may be unimpressed in the current straitened circumstances.

The range of provision for a given function such as maintenance dialysis might provide a guideline. We report the results of a survey undertaken from February to May 1986 of medical staffing in the 54 dialysis units for adults in the United Kingdom in relation to the number of patients receiving maintenance treatment in each unit.

\section{Methods}

A questionnaire sent in February 1986 to the 58 National Health Service dialysis units in the United Kingdom requested details of the population served, places available for hospital haemodialysis, numbers of patients receiving dialysis, and numbers and grades of medical staff. Reminders were sent out to those few that had not replied by the end of March and again in May. The concern felt by most of those working in the dialysis service can be gauged from the eventual reply rate of $100 \%$. For simplicity the patient load due to transplants and acute renal failure was not assessed, though several units mentioned one or both of these as being a sizeable proportion of their total workload. Answers that were unclear were checked personally with the unit concerned.

Replies from the four dialysis centres for children (London, Glasgow, Manchester, and Liverpool) are not included in this report. Replies from two of the 54 adult renal units (the RAF centre at Aylesbury serving the armed forces and the new unit at Preston, which had only one haemodialysed patient at the time of the survey) have also been excluded. Replies from the two units in Sheffield and the two units in Newcastle have been combined for each city because of the exchange of staff or patients, or both, between the units. Where there was more than one unit in other cities (Birmingham, 
Leeds, Manchester, Edinburgh, and Glasgow) they have been treated as separate units. The survey therefore analysed the data from 50 centres in the United Kingdom

The total patient load for each unit was defined as the sum of the number of patients receiving hospital maintenance haemodialysis, home haemodialysis, and continuous ambulatory peritoneal dialysis. In assessing the relation between total patient load and medical staffing not all "pairs of hands" were considered to be equal, as many units have to operate with middle grade or junior staff who rotate around different specialties of internal medicine every few months and are, in practice, still being trained in dialysis when they leave. This approach recognised that experienced long stay staff are generally more useful than others. A graded score was therefore allocated to each unit on the following basis:

Senior grade staff:

Wholly renal medical consultant or senior registrar

Renal and general medical consultant or senior registrar

Middle grade staff:

Wholly renal registrar or senior house officer

Renal and general medical registrar or senior house officer 2

For those units with surgical staff attached one point was added to the score for each surgeon. Associate specialists and research fellows were graded as senior registrars. Only 28 units listed preregistration or junior house officers as part of the staff. For this reason, and because in most units the house officers are temporary rather than permanent staff, the numbers of house officers, when present, have not been included in calculating the staff score.

The questionnaire asked for numbers of staff in each medical grade (consultant, senior registrar, registrar, senior house officer, and house officer) and did not specifically request information on the number of sessions a week. Respondents were asked only to allocate staff to one of two categories-namely, wholly renal duties or renal and general medical duties. In most replies a whole number was given. In some (four replies) a fraction of a whole number (for shared staff) was given. Where a respondent spontaneously provided information about sessions for any number of staff (seven replies) the appropriate proportion was taken into consideration in allocating the staffing score.

\section{Results}

Table I shows an analysis of the results. Twenty seven of the 50 units operated with at least one or more wholly renal staff; the rest ( 23 centres) operated with staff who also performed general medical duties. Staff funded by universities were attached to 13 units $(26 \%)$. Consultant surgical staff were attached to 30 units, all of which had transplant facilities; the remainder ( 20 centres) had no surgical staff. The number of senior medical staff in moderately sized dialysis units that had from 50 to 110 patients receiving the three forms of chronic dialysis ranged from only one consultant to three consultants and one senior registrar (table II). Most units of this size had two consultant physicians.

Thirty seven units had two to four middle grade staft. Although the total number of senior and middle grade staff tended to increase slightly with increasing numbers of patients, units with more senior grade staff did not seem to have fewer middle grade staff, or vice versa (fig 1 ). Units with two to

TABLE I-Patient load and staffing score for dialysis units in survey

\begin{tabular}{|c|c|c|c|c|c|c|c|c|c|c|c|c|c|}
\hline \multirow[b]{2}{*}{ Unit } & \multicolumn{3}{|c|}{$\begin{array}{l}\text { No of patients } \\
\text { receiving treatment }\end{array}$} & \multirow[b]{2}{*}{$\begin{array}{l}\text { Total } \\
\text { patient } \\
\text { load }\end{array}$} & \multirow[b]{2}{*}{$\begin{array}{l}\text { Con- } \\
\text { sultants }\end{array}$} & \multirow[b]{2}{*}{$\begin{array}{l}\text { Senior } \\
\text { registrar }\end{array}$} & \multirow[b]{2}{*}{ Registrar } & \multicolumn{5}{|c|}{ No of medical staff } & \multirow[b]{2}{*}{$\begin{array}{l}\text { Surgical } \\
\text { staff } \\
\text { attached }\end{array}$} \\
\hline & $\begin{array}{l}\text { Hospital } \\
\text { haemo- } \\
\text { dialysis }\end{array}$ & $\begin{array}{l}\text { Home } \\
\text { haemo- } \\
\text { dialysis }\end{array}$ & CAPD & & & & & SHO & $\begin{array}{l}\text { House } \\
\text { officer }\end{array}$ & $\begin{array}{l}\text { Staffing } \\
\text { score }\end{array}$ & $\begin{array}{l}\text { Wholly } \\
\text { renal }\end{array}$ & $\begin{array}{l}\text { University } \\
\text { funded }\end{array}$ & \\
\hline & 1 & & 4 & 5 & 2 & & 1 & 1 & 1 & 12 & & & \\
\hline $\begin{array}{l}1 \\
2\end{array}$ & $\begin{array}{r}12 \\
7\end{array}$ & 4 & 16 & $\begin{array}{l}12 \\
27\end{array}$ & $\begin{array}{l}0.5 \\
1\end{array}$ & & $\begin{array}{l}0.5 \\
1\end{array}$ & 2 & $\begin{array}{l}1 \\
1\end{array}$ & $\begin{array}{l}8 \cdot 1 \\
6^{\star}\end{array}$ & 1 & & $0 \cdot 1$ \\
\hline $\begin{array}{l}3 \\
4\end{array}$ & $\begin{array}{l}24 \\
25\end{array}$ & $\begin{array}{l}13 \\
33\end{array}$ & $\begin{array}{r}14 \\
3\end{array}$ & $\begin{array}{l}51 \\
61\end{array}$ & $\begin{array}{l}2 \\
2\end{array}$ & 2 & $\begin{array}{l}1 \\
1\end{array}$ & 1 & $\begin{array}{l}1 \\
1\end{array}$ & $\begin{array}{l}21 \\
12\end{array}$ & 2 & 3 & 2 \\
\hline 5 & 41 & 11 & 12 & 64 & 2 & 1 & 1 & 1 & & $16 \cdot 5$ & & & 0.5 \\
\hline 6 & 38 & 13 & 16 & 67 & 2 & & & 1 & & $10 \cdot 1^{\star}$ & & & $0 \cdot 1$ \\
\hline 7 & 30 & 13 & 28 & 71 & 1 & & 1 & 1 & 1 & 8 & & 1 & \\
\hline 8 & 32 & & 40 & 72 & 1 & 1 & 2 & 2 & & $17^{\star}$ & & & 1 \\
\hline 9 & 60 & & 12 & 72 & 3 & 1 & 1 & 1 & 1 & 30 & 7 & & 4 \\
\hline 10 & 14 & 50 & 9 & 73 & 1 & & 1 & 1 & $0 / 1$ & $8^{\star}$ & & & \\
\hline 11 & 17 & 29 & 30 & 76 & 1 & & 1 & 1 & 1 & $8 \cdot 3^{\star}$ & & & $0 \cdot 3$ \\
\hline 12 & 28 & 25 & 23 & 76 & 2 & & 1 & 1 & & $13^{\star}$ & & & 1 \\
\hline 13 & 24 & & 52 & 76 & 2 & 1 & 1.5 & 1 & & 18 & 2 & & \\
\hline 14 & 38 & & 46 & 84 & 2 & 1 & 3 & & 1 & 18 & & 1 & \\
\hline 15 & 67 & & 18 & 85 & 2 & & 1 & 1 & & 13 & 1 & & \\
\hline 16 & 26 & 30 & 30 & 86 & 2 & & 1 & 3 & & 21 & 4 & & 1 \\
\hline 17 & 16 & 19 & 52 & 87 & 2 & & 1 & 1.5 & $1 \cdot 5$ & 13 & & & \\
\hline 18 & 28 & 31 & 30 & 89 & 2 & & 1 & 2 & 1 & $17^{\star}$ & 3 & & \\
\hline 19 & 45 & & 48 & 93 & 3 & 1 & 2 & 2 & & 33 & 8 & 1 & 1 \\
\hline 20 & 22 & 37 & 69 & 128 & 2 & 1 & 1 & 2 & & 18 & & & \\
\hline 21 & 38 & 41 & 21 & 100 & 2 & 1 & 1 & 2 & 1 & $20^{\star}$ & & & 2 \\
\hline 22 & 13 & 42 & 50 & 105 & 3 & 1 & 1 & 2 & & $23^{\star}$ & & & 1 \\
\hline 23 & 46 & 17 & 44 & 107 & 2 & & 1 & 1 & & 16 & 3 & & 1 \\
\hline 24 & 18 & 62 & 28 & 108 & 1.8 & & 1 & 1 & 1 & $13 \cdot 1$ & 2 & & $0 \cdot 1$ \\
\hline 25 & 23 & 37 & 48 & 108 & 1 & $0+1$ & & 1 & & $11^{\star}$ & 1 & & \\
\hline 26 & 40 & 42 & 35 & 117 & 2 & & 1 & 1 & 1 & $14 \cdot 2$ & 2 & & 0.2 \\
\hline 27 & 43 & 28 & 46 & 117 & 2 & & 2 & 1 & 1 & 23 & 6 & & 4 \\
\hline 28 & & & & & & a confiden & & & & & & & \\
\hline 29 & 22 & 54 & 48 & 124 & 2 & & 1 & 2 & & 15 & 1 & & \\
\hline 30 & 26 & 46 & 53 & 125 & 2 & & 1 & 3 & & $16^{\star}$ & & & \\
\hline 31 & 41 & 55 & 37 & 133 & $3 \cdot 2$ & & 3 & 2 & & $30 \cdot 8$ & 8 & 1 & \\
\hline 32 & 37 & 58 & 39 & 134 & 3 & 1 & 2 & 4 & & 37 & 8 & 1 & 1 \\
\hline 33 & 75 & 59 & 13 & 147 & $1 \cdot 3$ & 1.5 & 2 & & & $15 \cdot 3$ & & & \\
\hline 34 & 35 & 31 & 82 & 148 & 3 & 2 & 1 & 2 & 2 & 27 & & & 1 \\
\hline 35 & 33 & 41 & 75 & 149 & 2 & 1 & 3 & 2 & 2 & 25 & 3 & & 2 \\
\hline 36 & 30 & 60 & 60 & 150 & 3 & 1 & 2 & 3 & & 35 & 9 & 1.2 & 2 \\
\hline 37 & 30 & 56 & 71 & 157 & 4 & 2 & 2 & 1 & 3 & 31 & & 4 & 1 \\
\hline 38 & 30 & 110 & 40 & 180 & $2 \cdot 6$ & 1 & 1 & 2 & 2 & 21 & & 0.6 & \\
\hline 39 & 32 & 86 & 65 & 183 & 2 & 1 & & 2 & 2 & 16.5 & & & 0.5 \\
\hline 40 & 72 & 60 & 56 & 188 & 2 & 1 & 2 & 2 & & 29 & 7 & & 2 \\
\hline 41 & 47 & 55 & 86 & 188 & 1 & 1 & 2 & 3 & 0.5 & 24 & 5.5 & 3 & 1 \\
\hline 42 & 47 & & 143 & 190 & 2 & 1 & 1 & 1 & 2 & 17 & & & 2 \\
\hline 43 & 40 & 69 & 93 & 202 & 4 & 2 & 2 & 2 & & 32 & 3 & 4 & 3 \\
\hline 44 & 20 & 136 & 50 & 206 & 2 & 1 & 1 & 2 & 2 & 17 & & & \\
\hline 45 & 30 & 110 & 70 & 210 & 2 & 1 & & 4 & & 27 & 2 & & 1 \\
\hline 46 & 54 & 126 & 61 & 241 & 2 & 1 & 1 & 2 & & 22 & 4 & & \\
\hline 47 & 59 & 100 & 95 & 254 & 2 & 1 & 2 & 3 & 2 & 26 & 5 & & 2 \\
\hline 48 & 76 & 24 & 166 & 266 & $2 \cdot 5$ & 2 & 1 & 5 & 1 & $40 \cdot 5$ & 8 & 2.5 & 0.5 \\
\hline 49 & 39 & 100 & 130 & 269 & 2 & 2 & $i$ & 1 & 1 & 22 & 3 & & \\
\hline 50 & 167 & 58 & 45 & 270 & 4 & & 1 & 4 & & 34 & 6 & & 1 \\
\hline
\end{tabular}


TABLE II-Dialysis units ${ }^{\star}$ in the United Kingdom showing numbers of senior and middle grade medical staff

\begin{tabular}{|c|c|c|c|c|c|c|c|c|c|c|c|c|}
\hline \multirow[b]{2}{*}{$\begin{array}{l}\text { No of } \\
\text { patients }\end{array}$} & \multicolumn{6}{|c|}{ No of senior grade staff (consultants: senior registrars) } & \multicolumn{6}{|c|}{ No of middle grade staff (registrars: SHOs) } \\
\hline & $\begin{array}{l}1 \\
1: 0\end{array}$ & $\begin{array}{l}2 \\
2: 0 \\
1: 1\end{array}$ & $\begin{array}{l}3 \\
2: 1\end{array}$ & $\begin{array}{l}4 \\
3: 1 \\
2: 2\end{array}$ & $\begin{array}{l}5 \\
3: 2\end{array}$ & $\begin{array}{l}6 \\
4: 2\end{array}$ & $\begin{array}{l}1 \\
1: 0 \\
0: 1\end{array}$ & $\begin{array}{l}2 \\
1: 1\end{array}$ & $\begin{array}{l}3 \\
2: 1 \\
1: 2 \\
3: 0\end{array}$ & $\begin{array}{l}4 \\
2: 2 \\
1: 3\end{array}$ & $\begin{array}{l}5 \\
1: 4 \\
2: 3 \\
3: 2\end{array}$ & $\begin{array}{l}6 \\
1: 5 \\
2: 4\end{array}$ \\
\hline$<50$ & $1 \dagger, 2 \ddagger$ & & & & & & 2 & & 1 & & & \\
\hline $50-110$ & $\begin{array}{l}7,10+ \\
11 \dagger\end{array}$ & $\begin{array}{l}4,6 \dagger, 8 \dagger \\
12,15,16, \\
17,18 \dagger, 23, \\
24 \ddagger, 25\end{array}$ & $\begin{array}{l}5,13 \\
14,21 \dagger\end{array}$ & $\begin{array}{l}3,9 \\
19, \\
22 \dagger\end{array}$ & & & $3,6,25$ & $\begin{array}{l}4,5,7, \\
9,10,11, \\
12,15,23, \\
24\end{array}$ & $\begin{array}{l}13 \ddagger, 14, \\
17 \ddagger, 18, \\
21,22\end{array}$ & $\begin{array}{l}8,16 \\
19\end{array}$ & & \\
\hline $115-160$ & & $\begin{array}{l}26,27 \\
29,30\end{array}$ & $\begin{array}{l}20,31 \neq \\
33 \neq, 35\end{array}$ & $\begin{array}{l}32 \\
36\end{array}$ & 34 & 37 & & 26,33 & $\begin{array}{l}20,27 \\
29,34 \\
37\end{array}$ & 30 & $\begin{array}{l}31,35, \\
36\end{array}$ & 32 \\
\hline $180-270$ & & 41 & $\begin{array}{l}39,40,42 \\
44,45,46 \\
47\end{array}$ & $\begin{array}{l}38 \neq \\
49 \\
50\end{array}$ & $48 \ddagger$ & 43 & & $\begin{array}{l}39,42, \\
49\end{array}$ & $\begin{array}{l}38,44, \\
46\end{array}$ & $\begin{array}{l}40,43, \\
45\end{array}$ & $\begin{array}{l}41,47 \\
50\end{array}$ & 48 \\
\hline
\end{tabular}

$\mathrm{SHO}=$ senior house officer.

${ }^{\star}$ Each unit has a reference number (table I) in order of increasing patient load (unit 28 omitted).

†Limited or no undergraduate teaching.

$\neq$ Fraction less than the whole number.

four senior grade staff had one to five (in only one instance six) middle grade staff, irrespective of the size of the unit (fig 1). Most units (70\%) had two to four senior grade members of staff and two to five at the middle grade. Excluding the two units with 12 and 27 patients, respectively, the three units with only one consultant and no senior registrar were Dundee, Derby, and Clwyd (fig 1).

Figure 2 shows the relation between total patient load and total staff score. Most units with fewer than 120 patients had staff scores from eight to 24 , which indicates a wide range of staff provision for similar patient loads. As even units with staff scores above 20 volunteered the information that they were overworked or understaffed the inference is not that midway between eight and 24 would be ideal but that all units of such a size should be aiming towards a staff score of greater than 20 . Those with more than 60 patients and scores of less than 10-that is, Dundee, Clwyd, and Derby-are obviously greatly understaffed. Two units with fewer than 100 patients had staff scores greater than 30 . London hospitals had a scatter of staff scores from 16 to 37 , with the staff of all but one having teaching duties in addition to clinical care. The larger units, with total patient loads from 180 to 270 , had staff scores ranging from 16 to 41 , again indicating a remarkably wide scatter of staff provision. Taking a narrower range of equivalent numbers of patients, the range of staff scores for units with 60 to 80 patients was eight to 31 and for 100 to 120 patients was 11 to 33 . In the larger units or centres with 240 to 270 patients the staff scores varied from 22 to 41 . The coefficient of determination for the relation $\left(r^{2}\right)$ was $0.24(p<0.001)$ (fig 2). Looked at from the other point of view a staff score from 16 to 18 applied to units with a patient load ranging in size from 70 to 205 , and a staff score of 20 to 22 applied to units with loads from 50 to 270 patients.

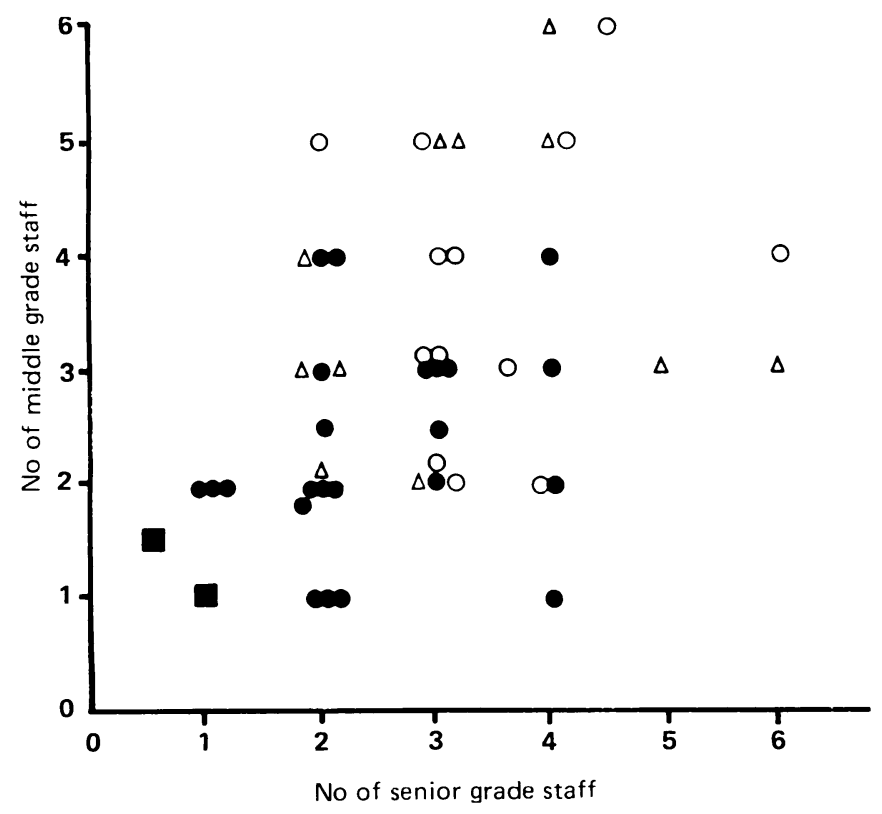

FIG 1-Relation between senior and middle grade staff. $\square=$ Units with $10-30$ patients, $=50-110$ patients; $\triangle=115-160$ patients; $\bigcirc=180-270$ patients.

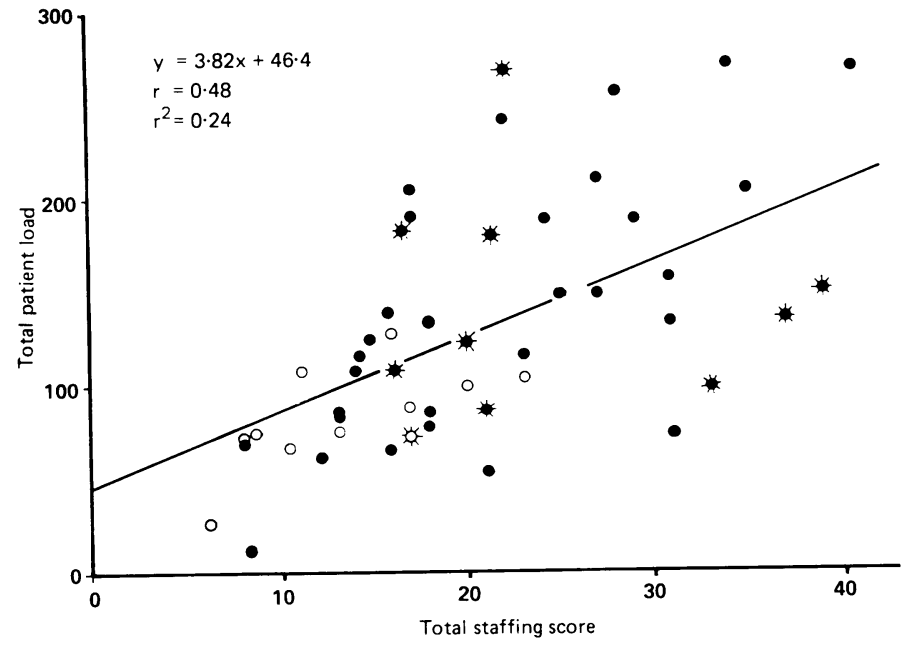

FIG 2-Total patient load in relation to staffing score in dialysis units in the United Kingdom. $=$ Teaching units. $\bigcirc=$ Units with no or limited undergraduate teaching. $=$ Units in London.

A simple unweighted patient to staff ratio varied widely (from six to 45) when calculated from total numbers of staff. Figure 3 shows how using the staff score to obtain a patient to staff score ratio effectively narrowed the range $(1 \cdot 5$ to $12 \cdot 1)$ for teaching units, non-teaching units, and the larger units. Although these categories overlapped, five of the 13 larger units seemed to be operating with a higher patient to staff score ratio than other units, but many other units, both teaching and non-teaching, were operating with patient to staff score ratios greater than seven. The most highly staffed units relative to patient load had patient to staff score ratios of less than four, with four less than three.

\section{Discussion}

The adequacy of resources for the treatment of renal failure, especially end stage failure, remains contentious. ${ }^{9}$ Consequently, provision in the United Kingdom, or parts thereof, has been assessed repeatedly, ${ }^{4}$ mainly from a regional viewpoint. Data on single units as described here remain scarce but are necessary for the appraisal of such units. ${ }^{5}$

It is extremely difficult to assess medical staffing in the whole nation, as members of staff in the same grade often spend different proportions of time on renal work. Inevitably some bias will be present in any survey of this kind. Some respondents may reply with a whole number referring to one post, while another may assess the same post differently-for example, as a fraction of a whole number-depending on the proportion of time spent in dialysis or renal service rather than on other work-for example, in general medicine or research. Apart from the difficulty of allocating time 


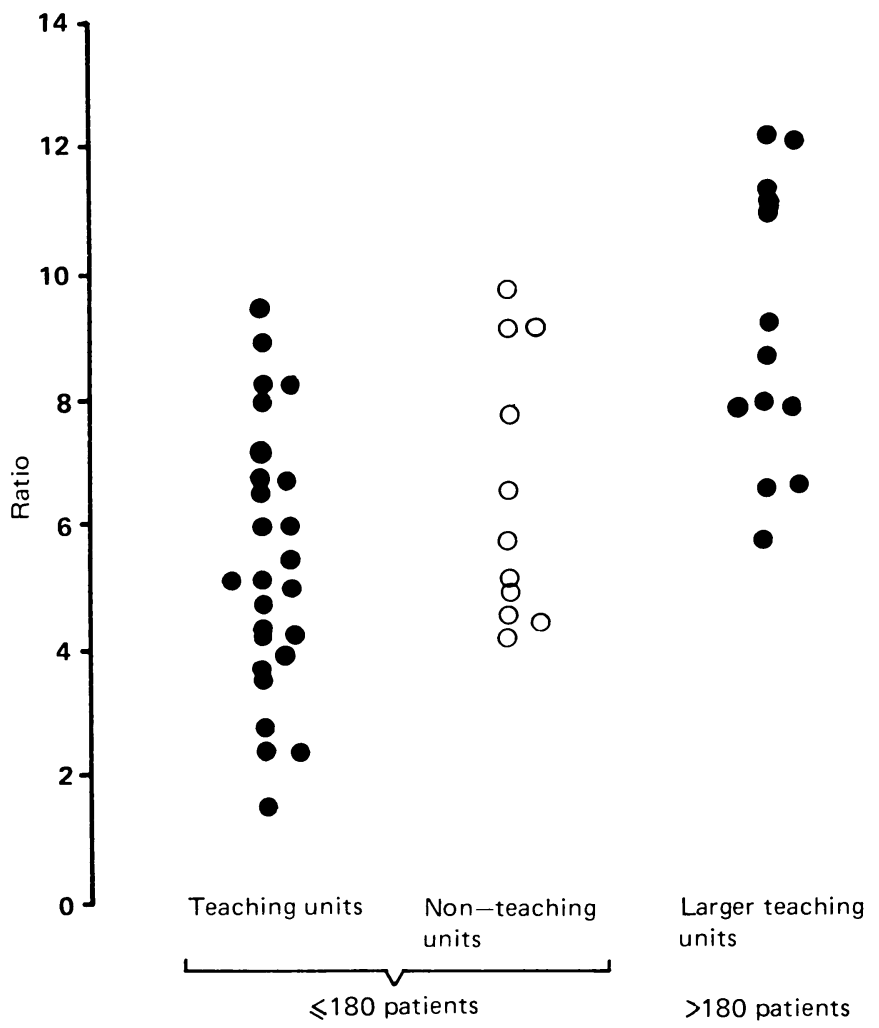

FIG 3-Ratios of total patient load to staffing score in dialysis units in the United Kingdom.

units when a member of staff in a renal unit has general medical duties as well additional bias is introduced when the member of staff is funded by a university and is notionally considered to be working part time in the renal service. The appropriate fraction is difficult enough to determine when the doctor is wholly renal and almost impossible to quantify when the university component also has to be considered for a member of staff with general medical as well as renal duties.

All doctors in the renal service know that, whatever the theoretical definition of their clinical sessions, in practice their time commitment depends on current demand from patients, and in an understaffed renal unit far more time will be spent on the care of renal patients than the nominal number of sessions implies. It is probably this inherent difficulty that has contributed to the lack of relevant staff surveys of single units. Bias, however, tends to be one way, the effect being to overestimate the staff provision. Most respondents gave a whole number for staff with other duties. Units may seem to be coping only because the staff will be using general medical, university, or even their private time to care for renal patients.

The main observation to emerge from this survey is the very wide range of the relation between total patient load and medical staff score. Even on a simple "pairs of hands" basis - that is, no loading for grade - the range would be wide. Determination of a national average would therefore be relatively meaningless. The inference is that those units with the lowest staff scores are understaffed and should be aiming to increase their staff score so that the range of staff provision relative to patient load is reduced. Even if the patient load due to transplants or acute renal failure, or both, is excluded (and such a load is not evenly distributed across the units) it is difficult to see how a unit with a staff score of only 11 can cope with 100 to 120 patients, while others with similar numbers of patients think they are not overstaffed with a staff score of 23 . At the same time one hospital is supporting just fewer than 100 patients with a staff score of 33 .

The argument that all units should be as well staffed (or as well equipped) as the best provided units has been termed the "keeping up with the Jones's" or "me too" syndrome. ${ }^{10}$ This is applicable when the "Jones's" are overprovided, but whether this is appropriate for most dialysis units in the current National Health Service is another matter. The clear impression gained from the volunteered comments of some of the respondents in this survey is that even the best provided units do not consider themselves to be overstaffed and that the underprovided units feel greatly overworked.

It could also be argued that if some units are coping with many patients and only a few staff then other units, with comparable patient loads and several more senior and middle grade staff could manage with less. Some have gone so far as to say that dialysis units need plentiful nursing staff but only minimal medical care. ${ }^{911}$ This viewpoint has been contested subsequently. ${ }^{13}$ Because the growth of dialysis units has mostly been a reaction to local circumstances rather than a prospectively planned development it is difficult to know where the most appropriate balance lies between the numbers of patients and staff or the best proportion of senior to junior staff. All that we can do is show the current range of patient to staff ratios in dialysis units, leaving single units to plead their own case in the light of the information provided.

The wide range of staff provision is indicative of the haphazard way in which single dialysis units in the United Kingdom have been driven to expand to meet patient need. The regional and population based surveys certainly have their place and will continue to be needed, but occasionally they can hide the fact that an understaffed individual centre ${ }^{5}$ is struggling to cope in an area that on paper seems to be adequately staffed according to national or regional criteria. ${ }^{16}$ Units operating at two different locations or hospitals in one area feel particularly overburdened, and medical staff consider that they are wasting the time spent travelling between two centres.

We do not suggest that the weighted scoring used here is ideal. It is only one possibility. Other investigators may devise a different or better system that can be used on the raw data. To assess progress, however, it is certainly worth performing surveys at regular intervals and applying some agreed simple definition for staff scoring.

The coefficient of determination between patient load and staff score $\left(r^{2}=0 \cdot 24\right)$ was fairly low. This effectively means that the number of patients accounted for only $24 \%$ of the observed variation in the staff score among centres. If all centres had adequate staff for their patient load a higher coefficient would be expected. We conclude that many dialysis units in the United Kingdom are probably understaffed for their total patient load in 1986 and that concerted action is needed to bring this to the attention of the relevant health boards.

Finally, owing to pressure from a few units concerned about the publication of identifiable data the anonymity of centres has been preserved. The need to hide the identity of dialysis units did not occur to us, and we think that it is debatable whether such secrecy is justifiable in a public service.

We thank sincerely the staff of all the United Kingdom dialysis units who gave of their time to reply to the questionnaire and thereby made this report possible.

\section{References}

1 de Wardener HE, Peart WS, Cattell WR, et al. Distribution of nephrological services for adults in Great Britain-report of the executive committee of the Renal Association. $\mathrm{Br}$ Med $\mathcal{f}$ 1976;ii:903-6.

2 Dowie R. Deployment of resources in treatment of end stage renal failure in England and Wales. BrMed f 1984;288:988-91.

3 Giles G, Davison AM Are renal services efficient? Health and Social Services Joumal 1985 May: $546-8$.

4 Jones NF, Goodwin FJ, Roberts AP. Manpower and workload in adult renal medicine in the United Kingdom 1975-82. BrMed f 1984;288:992-4.

5 Eastwood JB, Maxwell JD, Saunders KB. Treatment of end stage renal disease. Br Med $\mathcal{J}$ 1984;288: 1455 .

6 Brunner FP, Broyer $\mathrm{M}$, Brynger $\mathrm{H}$, et al. Combined report on regular dialysis and transplantation in Europe, XV, 1984. Proc Eur Dial Transplant Assoc 1985;22:3-53.

7 King Edward's Hospital Fund for London. Nursing staff_considerations on standards of staffing. London: Geo Barber, 1945.

8 Fuller C. Staffing a dialysis unit. Nursing Times 1984;80:59-61.

9 McCarthy M. Treatment of end stage renal disease. Br Med f 1984;288:1306-7.

10 Davidson $\mathrm{L}$. The acquisition and development of technical resources: a personal view. Health Bull (Edinb) 1984;42:5-13.

11 Gabriel R. Chronic renal failure in the United Kingdom: referral, funding and staffing. In: Parsons FM, Ogg CS, eds. Renal failure-who cares? Lancaster: MTP Press, 1983:35-40. 12 Nicholls A, Feest T. Treatment of end stage renal disease. Br Med f 1984;288:1533-4.

(Accepted I September 1986) 